\title{
The Effect of Perceived Teacher Behaviors on Students' Self-Esteem and Attitudes Towards Learning
}

\author{
Meral Sert Agir ${ }^{1}$ \\ ${ }^{1}$ Ataturk Education Faculty, Marmara University, Istanbul, Turkey \\ Correspondence: Meral Sert Agir, Ataturk Education Faculty, Marmara University, Istanbul, Turkey. E-mail: \\ meralagir@marmara.edu.tr
}

Received: July 30, 2019

Accepted: August 20, 2019 Online Published: September 20, 2019

doi:10.5539/jel.v8n5p203

URL: https://doi.org/10.5539/jel.v8n5p203

\begin{abstract}
While it depends on many factors for the teacher to achieve the assumed mission apart from themselves, the quality of the relationship established between the teacher and student is among the prominent factors that enable the student to reach the target behaviors. Considering the role of educational institutions as the protective factor for students and the efficiency of teachers in this process, the main purpose of this research was determined as examining the effect of the perceived teacher behaviors on the self-esteem of students and their attitudes towards learning. 306 students randomly selected from among the 9th, 10th and 11th grades from Anatolian high schools in Kadikoy, Istanbul were applied scales of Perceived Teacher Behaviors, Self-Esteem and Attitudes towards Learning, and the obtained data was analyzed by Pearson Moments Correlation and Regression Analysis techniques. The findings revealed that the perceived teacher attitudes and its sub-dimensions were negatively and weakly correlated with self-esteem, moderately positive and weakly correlated with attitudes toward learning scale sub-dimensions ( $p<0.05 ; \mathrm{p}<0.01)$. According to results, it was determined that the perceived teacher behaviours negatively affected the self-esteem and positively affected the nature of learning, expectation and openness dimensions in the sub-dimensions of the attitudes towards learning and negatively affected the learning-related anxiety. It was found that while 7\% change in self-esteem is explained by Factor 2 (positive teacher behaviors) and this factor negatively affected the self-esteem; Factor 2 on the anxiety dimension of the attitudes about learning and Factor 1 and Factor 3 explaining the behaviors of teachers that are considered within the scope of emotional abuse explain the $15 \%$ of the change in anxiety, and that these factors negatively affected anxiety; Factor 1 and Factor 4 (negative teacher behaviors) Factor 2 (positive teacher behaviors) explained 19\% of the change in the dimension of openness to learning, and these factors had a negative effect on the dimension of openness.
\end{abstract}

Keywords: perceived teacher behaviours, teachers' maltreatments, self-esteem, learning attitudes

\section{Introduction}

Teachers undertake an important mission in raising qualified manpower by realizing the objectives of the education system in the classroom environment. The main duty of the teachers is to create behavior change in the students in line with the learning process and objectives. The ability of teachers' expertise and knowledge on pedagogical formation to have the expected effect on the student depends on the teacher-student relationship. The relationship of the teacher with the student may depend on a number of factors such as the environment in which the school is located, school culture and climate, educational program and equipment besides the characteristics of the teacher. However, for the students, the attitudes of the teacher in the classroom, that is, their thoughts, feelings and behaviors towards the students, are more important (Burnett, 1999).

Although the behaviors that the student expects from the teacher vary depending on the dynamics of development at each stage of teaching, the expectation for the form of relationship based on trust, love and unconditional acceptance, which are the basic building blocks of all human relationships, does not change. As a human being in the classroom environment, the student demands to experience the dynamics of the basic human relationship with the teacher, the other person, from whom he/she expects to secure his/her own development, through their position (Frenzel, Goetz, Lüdtke, Pekrun, \& Sutton, 2009; Feuerborn \& Chinn, 2012). Therefore, warm attention, love, friendship, trust and tolerance should take place under the umbrella of leadership and guidance in the teacher's actions regarding the teaching process. The student's positive perception of the classroom climate (Way, Reddy, \& Rhodes, 2007; Wang, Selman, Dishion, \& Stormshak, 2010) is formed by a fair performance assessment and, 
accordingly, sense of confidence that he/she can be given the support he/she needs. Discipline in the teaching environment is a supportive practice for the student to acquire self-management skills by formulating the necessary adjustments with the student (Lewis, 2001) in order to achieve the determined goals (Twyman \& Heward, 2018). In other words, it is the ability of the teacher to employ the behavioral patterns necessary for the student to manage his or her own learning (Lemos, 1999). In addition, the teacher is the authority figure that will enable the student to perceive himself/herself as valuable and sufficient. In a sense, the student proves his/her competence and value to the group to which he/she belongs, that is, to his/her classmates, through the teacher who is the leader of the class. The teacher, who settles in the position of expert of the family in childhood with the knowledge he/she has, gives the information that he/she is capable of performing the roles and requirements of an adult world during adolescence. Therefore, he/she plays a facilitating role for meeting the student's needs of acceptance and being valued among his/her peers (Wentzel, 1994), and recognition as an individual.

It is seen that the student's positive impression of his/her relationship with the teacher not only ensures the achievement of the academic objectives of education and training (Gorham \& Christopher,1992; Yuns, Osman, \& Ishak, 2011), but it also plays a supporting role in healthy psycho-social development (Noels, Clément, \& Pelletier, 1999). Given that development is a whole and all areas of development affect each other, naturally, the definition of self of the student can also be positive, who is guaranteed to achieve his/her teaching goals in the classroom environment. Research shows that students with high academic performance have higher self-efficacy, self-esteem, self-worth, and exhibit self-control personality traits (Zimmerman, Bonner, \& Kovach, 1996; Schunk \& Miller, 2002; Baumeister, Campbell, Krueger, \& Vohs, 2003). In addition, it is emphasized that these students differ in terms of their attitudes towards learning and that their willingness and interest towards learning is high (Gorham \& Christophel, 1992; Roorda, Koomen, Spilt, \& Oort, 2011).

Although the behaviors that the students expect from the teachers are naturally the professional functions of the individuals (experts) who will perform the teaching profession after specialization and pedagogical formation education, contrary to the expectations, teachers may exhibit many negative behaviors that prevent the fulfillment of the functions of the profession (Fields, 1996; Lewis, 2001; Kearney, Plax, Hays, \& Ivey, 1991). In other words, it is seen that teachers have preventive negative behaviors and practices rather than guaranteeing healthy development of students besides acquiring target behaviors, depending on the traditional understanding of education or personality traits (Wayne \& Youngs, 2003; Kelsey, Kearney, Plax, Allen, \& Ritter, 2004). The traditional education and authoritarian discipline understanding describe the student's position in the teaching process as "passive recipients of knowledge". The teacher, on the other hand, acts as an active, informative person and as an authority figure that must be obeyed. In other words, class management is structured with the power produced by the authority, rather than the power of authority produced by the knowledge. In the classroom management, where traditional and reactive understanding prevails, the relationship between the teacher and the student is limited under the control of the teacher (Lewis, 2001). Punishment is perceived as a part of classroom management or disciplinary process and the unwanted behaviors of the student are tried to be changed with the first type or second type of punishment methods (Cohen \& Amidon, 2004). The first type of punishments are practices that leave traces on the student and damages them physiologically or psychologically (beating, severe humiliation and insult targeting personality). The second type of punishments are based on deprivation; these are practices based on depriving the student of an activity he/she likes to do or an object he/she likes for a certain period of time if he/she displays unwanted behavior, such as not letting the student to take a break, not giving chocolate (Shields \& Gredler, 2003). Research shows that teachers who perceive punishment as a disciplinary approach resort to the first type of punishment methods, and by applying the deprivation punishment method in a way that is not appropriate to its content, they can create the effect of the first type of punishment (Weijers, 2000; Sutton \& Swettenham, 1999). In addition, it is stated that teachers exhibit many behaviors that cause psychological pressure such as rejection, humiliation, ignoring, leaving alone, expectation above someone's developmental period and competences, intimidation, deprivation of support, lack of emotional response, etc., through verbal or non-verbal communication techniques (Hyman \& Perone, 1998; Brendgen, Wanner, \& Vitaro, 2006; Chen \& Wei, 2011). All of these negative behaviors are defined in the literature on child abuse as psychological, emotional abuse and physiological abuse (Straus, 2000; Emery \& Laumann-Billings, 2002). Studies on abuse point out that behaviors in the scope of child abuse and neglect in the family are also widely used in the teacher-student relationship (Elbedour, Assor, Center, \& Maruyama, 1997). While the effects of physical abuse can be directly observed, the effects of emotional abuse on children/students are more difficult to measure. However, disruption, pause or decline in the psycho-social development process can increase the psycho-social predisposition to many long-term behavior and adaptation problems such as low self-worth, damage to self-esteem, deterioration in interpersonal relationships, and suicidal tendencies (Piekarska, 2000; Marlow, Goodman, Meltzer, \& Ford, 2013; Fromuth, Davis, Kelly, \& Wakefield, 2015). Naturally, exposure to such negative behaviors leads to a change in 
attitudes toward learning, in other words, inadequacy of learning (Lewis \& Riley, 2009), lack of control over one's own life, learned desperation and hopelessness, and the disbelief that learning or education will make any difference in one's own life, etc., and a decrease in interest and willingness to learn (Snoock, 1999; Sava, 2002; McEachern, Aluede, \& Kenny, 2008; Goodboy \& Bolkan, 2009). Therefore, the decline in academic performance paves the way for many problems ranging from school absenteeism (Slade \& Wissow, 2007; Kurtz, Gaudin Jr, Wodarski, \& Howing, 1993), drop-out and unhealthy professional orientation.

Teachers, on the other hand, realize the change in students through negative attitudes towards learning and the decline in academic performance. In traditional, authoritarian discipline understanding, the difference in academic performance, and behavior and adjustment problems are often associated with the student and the student's environment, family (Campbell \& Verna, 2007) and peer environment (Wentzel, 1994). In other words, teachers' focusing on teaching objectives (acquisition of content) with the thought that they apply the "rights" of traditional education approach may lead to ignoring the psycho-social dynamics of teacher-student relationship.

As a result, although the educational institution's ability to meet social expectations depends on the effective use of a number of resources such as curriculum, hardware, etc., teachers, who are the human resource responsible for the achievement of the special objectives of education, are seen to be factors affecting the process. What is expected of the teacher is the upbringing of healthy individuals responsible for their own learning, which will guide the development of societies, which is the main starting point of all functions. Therefore, teachers should be able to produce student-teacher relationships that will ensure the acquisition of behaviors that will improve the quality of life of the learner by supporting the learning process due to the nature of development. In this context, with the thought of contributing to the studies aimed at changing the nature of the student relationship, the main purpose of this study was to determine the effect of perceived teacher behaviors on students' self-esteem and attitudes towards learning.

\section{Method}

The study is based on the relational screening method and relational screening methods are research methods that try to determine the existing situation between two or more variables in a relational manner (Karasar, 2007).

\subsection{Purpose of the Research}

The main purpose of this study was to determine the effect of perceived teacher behaviors on students' self-esteem and attitudes towards learning. With this research, it was tried to determine to what extent perceived teacher behaviors predict students' self-esteem and attitudes towards learning. Within the framework of this main objective, the study examined the predictive level of perceived teacher behavior sub-dimensions on self-esteem and attitudes toward learning, and their sub-dimensions.

\subsection{Sample of the Research}

The research was carried out in the 2015-2016 academic year with random students of 9th, 10th and 11th grades selected from randomly determined high-school level state schools that are located in the Kadıköy district of Istanbul and the institution permission for the research was provided by the Provincial Directorate of National Education of Istanbul Governorship with the Date 21.04.2106 and the Number 59090411-20-E.4519158. The research was carried out in collaboration with school management and teachers as well as four students who received training on the application of the scales among the students of Marmara University Atatürk Education Faculty, Psychological Counseling and Guidance Department. In addition, the researcher was personally worked in each school to solve unexpected problems that could affect the data collecting process. During the course of the applications, it was tried to control the factors that might prevent the students from responding objectively, such as the attitude of the teacher in the classroom. Out of 360 students who participated in the study, the data of 306 students, 187 males and 119 females, were analyzed. The research did not include 12th-grade students as they were preparing for the entrance examination for higher education. Data on the demographic characteristics of the students included in the study are presented in Table 1. 
Table 1. Demographic characteristics of students

\begin{tabular}{llll}
\hline & & $\mathrm{n}$ & $\%$ \\
\hline Gender & Male & 187 & 61.1 \\
& Female & 119 & 38.9 \\
& 11 & 1 & 3 \\
& 12 & 0 & .0 \\
& 13 & 0 & .0 \\
& 14 & 8 & 2.6 \\
& 15 & 134 & 43.8 \\
& 16 & 103 & 33.7 \\
Grade & 17 & 42 & 13.7 \\
& 18 & 18 & 5.9 \\
& 9 th Grade & 84 & 53.3 \\
& 10 th Grade & 58 & 27.6 \\
& 11 th Grade & 58.0 \\
\hline
\end{tabular}

\subsection{Data Collection Tools}

Perceived Teacher Behaviors Scale was used to measure students' perceived teacher behaviors, Self-Esteem Scale was used to measure their Self-esteem, Attitude Towards Learning Scale was used to measure their Attitude Towards Learning, and a personal information form prepared by the researcher was used to obtain the demographic information of the students.

\subsubsection{Perceived Teacher Behaviors Scale (PTBS)}

The scale was devised by Alantar (1989) and Çakar (1994) under the supervision of Erkmanin order to measure teacher abusive behavior perceived byadolescents. The scale was created by Alantar (1989) with 16 items and later developed by Çakar (1994) to include 60 items. The reliabilitystudyfor the scale was repeated by Barsin (1999). While the first form of the scale had 74 items, upon testing internal consistency, it was rearranged to include 60 items, 18 of which were reverse-items. Cronbach's alpha coefficient of the scale was .915 , and its test-retest reliability coefficientwas .70 . The scale is an inventory that can be administered to groups and be applied by individuals themselves without time limitation. The items of the Likert-type scale are marked according to 4-point Likert scale. Depending on the frequency of behaviors, the items of the scaleshouldbemarked with one of the following: "almost always" (4 points), "often" ( 3 points), "rarely" ( 2 points), "almost never" ( 1 point).

\subsubsection{The Scale of Attitudes Toward Learning}

The scale of attitudes toward learning was prepared as a five-point Likert scale consisting of 40 questions developed by Kara (2010). The scale consists of four sub-dimensions: the nature of learning, learning anxiety, expectation, and openness. The Cronbach Alpha internal consistency coefficient of the Scale was calculated as .73 and the test re-correlation coefficient was calculated as .87. The Cronbach Alpha value of this study according to factor analysis for the sample group was found to be .775 .

\subsubsection{Rosenberg Self-Esteem Scale (RSES)}

The Rosenberg Self-Esteem Scale, which was developed by Morris Rosenberg (1965) and adapted to Turkish by Çuhadaroğlu (1986), consists of 63 items and 12 sub-scales. These sub-scales can be used separately according to the purpose of the research (Gray-Little, Williams, \& Hancock, 1997). The self-esteem sub-scale consists of 10 items. In this study, self-esteem sub-scale was used to measure self-esteem for the main purpose of the study. The subjects score between 0 and 6 based on the evaluation system internal to the scale. The higher the score, the lower the level of self-esteem. According to this scale, $0-1$ points is a high level of self-esteem, $2-4$ points is a moderate level of self-esteem, and 5-6 points is a low level of self-esteem. The test-repeat reliability of the scale is .89 and its validity is .71 .

\subsection{Data Analysis}

The data were analyzed using SPSS 22 program with a 95\% confidence level. Kurtosis and skewness values obtained from intra-item scales being between +3 and -3 were deemed to be enough for normal distribution (Groeneveld \& Meeden, 1984; Moors, 1986; Hopkins \& Weeks, 1990; De Carlo, 1997). For this reason, the relationship between scale scores was analyzed with Pearson correlation test, which is a parametric test technique. Pearson Correlation is used to examine the direction and strength of the relationship between two quantitative variables. Regression test was applied to examine the effect of perceived teacher attitudes on self-esteem and attitude towards learning. Regression analysis is a test technique which examines the effect of a single dependent 
variable or multiple dependent variables on a dependent variable.

\section{Findings}

Table 2. Descriptive statistics of scale scores

\begin{tabular}{llllllll}
\hline & $\mathrm{n}$ & Minimum & Maximum & Mean & SD & Skewness & Kurtosis \\
\hline Self-esteem & 306 & 0.00 & 4.51 & 1.44 & 0.89 & 1.147 & 1.332 \\
Factor 1 & 306 & 20.00 & 65.00 & 52.61 & 10.25 & -.831 & -.189 \\
Factor 2 & 306 & 22.00 & 60.00 & 42.07 & 6.70 & -.133 & -.202 \\
Factor 3 & 306 & 15.00 & 51.00 & 37.02 & 8.00 & -.491 & -.358 \\
Factor 4 & 306 & 13.00 & 30.00 & 22.30 & 3.55 & -.259 & -.312 \\
Perceived Teacher Behavior & 306 & 85.00 & 203.00 & 154.00 & 22.91 & -.288 & -.724 \\
The Nature of Learning & 306 & 14.00 & 35.00 & 27.61 & 4.97 & -.447 & -.428 \\
Learning-Related Anxiety & 306 & 12.00 & 52.00 & 34.99 & 7.93 & -.605 & .094 \\
Expectation & 306 & 13.00 & 45.00 & 35.14 & 6.59 & -.394 & -.558 \\
Openness & 306 & 22.00 & 55.00 & 39.83 & 6.79 & -.158 & -.590 \\
\hline
\end{tabular}

Note. Factor 1: discipline-rejection; Factor 2: warmth-acceptance, democratic positive self-concept; Factor 3: discipline double bind belittling indifference; Factor 4: demand-high expectation sexual abuse respect to individuality.

The participants who answered the questionnaire have the following results (see Table 2);

They have a mean self-esteem score of $1.44 \pm 0.89$, skewness coefficient of 1.147 and a kurtosis coefficient of 1.332. They have a Factor 1 score average of $52.61 \pm 10.25$ with a skewness coefficient of -.831 and a kurtosis coefficient of -.189; Factor 2 score average of $42.07 \pm 6.7$ with a skewness coefficient of -.133 and a kurtosis coefficient of -.202; Factor 3 score average of $37.02 \pm 8.00$ with a skewness coefficient of -.491 and a kurtosis coefficient of -.358; Factor 4 score average of $22.30 \pm 3.55$ with a skewness coefficient of -.259 and kurtosis coefficient of -.312 ; and a Perceived Teacher Behavior score average of $154.00+22.91$ with a skewness coefficient of -.288 and a kurtosis coefficient of -.724 .

They have a Nature of Learning score average of $27.61 \pm 4.97$ with a skewness coefficient of -.447 and a kurtosis coefficient of -.428; Anxiety of Learning score average of $34.99 \pm 7.93$ with a skewness coefficient of -.605 and a kurtosis coefficient of -.094; Expectation score average of $35.14 \pm 6.59$ with a skewness coefficient of -.394 and a kurtosis coefficient of -.558 , and Openness score average of $39.83 \pm 6.79$ with a skewness coefficient of -.158 and a kurtosis coefficient of -.590 .

Table 3. The relationship between scale scores

\begin{tabular}{llllllll}
\hline & & Self-esteem & Factor 1 & Factor 2 & Factor 3 & Factor 4 & Perceived Teacher Behavior \\
\hline Self-esteem & $\mathrm{r}$ & 1 & $-.207^{* *}$ & $-.205^{* *}$ & $-.219^{* *}$ & $-.174^{* *}$ & $-.256^{* *}$ \\
& $\mathrm{p}$ & & .000 & .000 & .000 & .002 & .000 \\
\multirow{5}{*}{ The Nature of Learning } & $\mathrm{n}$ & 306 & 306 & 306 & 306 & 306 & 306 \\
& $\mathrm{r}$ & .004 & $.225^{* *}$ & $.215^{* *}$ & .022 & $.153^{* *}$ & $.195^{* *}$ \\
& $\mathrm{p}$ & .938 & .000 & .000 & .698 & .007 & .001 \\
Learning-Related Anxiety & $\mathrm{n}$ & 306 & 306 & 306 & 306 & 306 & 306 \\
& $\mathrm{r}$ & $.230^{* *}$ & $-.341^{* *}$ & $-.304^{* *}$ & $-.373^{* *}$ & $.370^{* *}$ & $-.429^{* *}$ \\
& $\mathrm{p}$ & .000 & .000 & .000 & .000 & .000 & .000 \\
Expectation & $\mathrm{n}$ & 306 & 306 & 306 & 306 & 306 & 306 \\
& $\mathrm{r}$ & $-.113^{*}$ & $.262^{* *}$ & $.372^{* *}$ & $.150^{* *}$ & $.284^{* *}$ & $.322^{* *}$ \\
\multirow{3}{*}{ Openness } & $\mathrm{p}$ & .049 & .000 & .000 & .009 & .000 & .000 \\
& $\mathrm{n}$ & 306 & 306 & 306 & 306 & 306 & 306 \\
& $\mathrm{r}$ & -.079 & $-.392^{* *}$ & $.266^{* *}$ & $.332^{* *}$ & $.355^{* *}$ & $.424^{* *}$ \\
\hline
\end{tabular}

Note. $\mathrm{p}^{*}<0.05, \mathrm{p}^{* *} 0.01 ; \mathrm{p} 0.05=$ no correlation.

There is a weak negative relationship between Self-Esteem and Factor $1(\mathrm{r}=-.207)$, a weak negative relationship between Self Esteem and Factor $2(\mathrm{r}=-205)$, a weak negative relationship between Self-Esteem and Factor 3 ( $\mathrm{r}=$ -.219), a weak negative relationship between Self-Esteem and Factor 4 ( $\mathrm{r}=-.174)$, and a weak negative relationship between Self-Esteem and Perceived Teacher Behavior $(r=-.256)$ (see Table 3). 
There is a weak positive relationship between Nature of Learning and Factor $1(\mathrm{r}=.225)$, a weak positive relationship between Nature of Learning and Factor $2(\mathrm{r}=.215)$, a weak positive relationship between Nature of Learning and Factor $4(\mathrm{r}=.153)$, and a weak positive relationship between Nature of Learning and Perceived Teacher Behavior $(r=.195)$ (see Table 3$)$.

There is a weak positive relationship between Learning Anxiety and Self-Esteem $(r=.230)$, a medium negative relationship between Learning Anxiety and Factor $1(\mathrm{r}=-.341)$, a medium negative relationship between Learning Anxiety and Factor $2(\mathrm{r}=-.304)$, a medium negative relationship between Learning Anxiety and Factor $3(\mathrm{r}=$ -.373), a medium negative relationship between Learning Anxiety and Factor $4(\mathrm{r}=.370)$ and a medium negative relationship between Learning Anxiety and Perceived Teacher Behavior $(r=-.429)$ (see Table 3).

There is a weak negative relationship between Expectation and Self-Esteem $(\mathrm{r}=.-113)$, a weak positive relationship between Expectation and Factor $1(\mathrm{r}=.262)$, a weak positive relationship between Openness and Factor $2(\mathrm{r}=.150)$, a weak positive relationship between Openness and Factor $3(\mathrm{r}=.150)$, a weak positive relationship between Openness and Factor $4(\mathrm{r}=.284)$, and a medium positive relationship between Expectation and Perceived Teacher Behavior $(\mathrm{r}=.322)$. There is a medium positive relationship between Openness and and Factor $1(\mathrm{r}=.392)$, a medium positive relationship between Openness and Factor $2(\mathrm{r}=.266)$, a medium positive relationship between Openness and Factor $3(\mathrm{r}=.332)$, a medium positive relationship between Openness and Factor $4(\mathrm{r}=.355)$, and a medium positive relationship between Openness and Perceived Teacher Behavior $(\mathrm{r}$ $=.424)$ (see Table 3$)$.

Table 4. The effect perceived teacher behavior on self-esteem (tegression)

\begin{tabular}{llllllll}
\hline Dependent Var. & Independent Var. & $\mathrm{F}$ & $\mathrm{p}$ & Coefficient (B) & $\mathrm{t}$ & $\mathrm{p}$ & $\mathrm{R}^{2}$ \\
\hline Self-esteem & Constant & 21.390 & .000 & 2.977 & 8.832 & .000 & .066 \\
& Perceived Teacher Behavior & & & -.010 & -4.625 & $.000^{*}$ & \\
\hline
\end{tabular}

Note. $\mathrm{p}^{*}<0.05=$ there is an effect.

The results of the regression analysis carried out to examine the effects of Perceived Teacher Behavior, on Self-Esteem are provided on the Table 4. The regression model created according to the results of the analysis was found to be statistically significant $(\mathrm{p}<0.05)$. When the coefficient was examined in the model, it was determined that Perceived Teacher Behavior had a negative effect on Self-Esteem $(B=-.010 ; p<0.05) .7 \%$ of the change in Self Esteem is explained by Perceived Teacher Behavior.

Table 5. The effect of perceived teacher behavior on the nature of learning

\begin{tabular}{llllllll}
\hline Dependent Var. & Independent Var. & $\mathrm{F}$ & $\mathrm{p}$ & Coefficient (B) & $\mathrm{t}$ & $\mathrm{p}$ & $\mathrm{R}^{2}$ \\
\hline The Nature of Learning & Constant & 12.045 & .001 & 21.087 & 11.095 & .000 & .038 \\
& Perceived Teacher Behavior & & & .042 & 3.471 & $.001^{*}$ & \\
\hline
\end{tabular}

Note. $\mathrm{p}^{*}<0.05=$ there is an effect.

The results of the regression analysis conducted to investigate the effect of Perceived Teacher Behavior on the nature of learning are provided on the Table 5 . The regression model created according to the results of the analysis was found to be statistically significant $(\mathrm{p}<0.05)$.

When the coefficient was examined within the model, it was determined that Perceived Teacher Behavior had a positive effect on the Nature of Learning $(B=.042 ; \mathrm{p}<0.05) .4 \%$ of the change in the Nature of Learning is explained by Perceived Teacher Behavior.

Table 6. The effect of perceived teacher behavior on learning anxiety (regression)

\begin{tabular}{llllllll}
\hline Dependent Var. & Independent Var. & $\mathrm{F}$ & $\mathrm{p}$ & Coefficient (B) & $\mathrm{t}$ & $\mathrm{p}$ & $\mathrm{R}^{2}$ \\
\hline Learning-Related Anxiety & Constant & 68.577 & .000 & 57.847 & 20.731 & .000 & .184 \\
& Perceived Teacher Behavior & & & .148 & -8.281 & $.000^{*}$ & \\
\hline
\end{tabular}

Note. $\mathrm{p}^{*}<0.05=$ there is an effect.

The results of the regression analysis conducted to investigate the effect of Perceived Teacher Behavior on 
Learning Anxiety are provided on the Table 6. The regression model created according to the results of the analysis was found to be statistically significant $(p<0.05)$. When the coefficient was examined within the model, it was found that Perceived Teacher Behavior negatively affected Learning Anxiety $(B=-.148 ; p<0.05) .18 \%$ of the change in Learning Anxiety is explained by Perceived Teacher Behavior.

Table 7. The effect of perceived teacher behavior on expectation (regression)

\begin{tabular}{llllllll}
\hline Dependent Var. & Independent Var. & $\mathrm{F}$ & $\mathrm{p}$ & Coefficient (B) & $\mathrm{t}$ & $\mathrm{p}$ & $\mathrm{R}^{2}$ \\
\hline Expectation & Constant & 35.236 & .000 & 20.873 & 8.588 & .000 & .104 \\
& Perceived Teacher Behavior & & & .093 & 5.936 & $.000^{*}$ & \\
\hline
\end{tabular}

Note. $\mathrm{p}^{*}<0.05=$ there is an effect.

The results of the regression analysis conducted to investigate the effect of Perceived Teacher Behavior on Expectation are provided on the Table 7. The regression model created according to the results of the analysis was found to be statistically significant $(\mathrm{p}<0.05)$. When the coefficient was examined within the model, it was determined that Perceived Teacher Behavior had a positive effect on Expectation $(B=.093 ; \mathrm{p}<0.05) .10 \%$ of the change in Expectation is explained by Perceived Teacher Behavior.

Table 8. Investigation of the effect of perceived teacher behavior on openness (regression)

\begin{tabular}{llllllll}
\hline Dependent Var. & Independent Var. & $\mathrm{F}$ & $\mathrm{p}$ & Coefficient (B) & $\mathrm{t}$ & $\mathrm{p}$ & $\mathrm{R}^{2}$ \\
\hline Openness & Constant & 66.759 & .000 & 20.464 & 8.542 & .000 & .180 \\
& Perceived Teacher Behavior & & & .126 & 8.171 & $.000^{*}$ & \\
\hline
\end{tabular}

Note. $\mathrm{p}^{*<0.05}=$ there is an effect.

The results of the regression analysis conducted to investigate the effect of Perceived Teacher Behavior on Openness are provided on the Table 8 . The regression model created according to the results of the analysis was found to be statistically significant $(\mathrm{p}<0.05)$.

When the coefficient was examined within the model, it was determined that Perceived Teacher Behavior had a positive effect on Openness $(\mathrm{B}=.126 ; \mathrm{p}<0.05) .18 \%$ of the change in Openness is explained by Perceived Teacher Behavior.

Table 9. Investigation of the effect of perceived teacher behavior factors on self-esteem (regression)

\begin{tabular}{llllllll}
\hline Dependent Var. & Independent Var. & $\mathrm{F}$ & $\mathrm{p}$ & Coefficient (B) & $\mathrm{t}$ & $\mathrm{p}$ & $\mathrm{R}^{2}$ \\
\hline Self-esteem & Constant & 5.880 & .000 & 3.117 & 8.150 & .000 & 0.073 \\
& Factor 1 & & & -.003 & -.374 & .709 & \\
& Factor 2 & & & -.020 & -2.525 & $.012^{*}$ \\
& Factor 3 & & & -.016 & -1.536 & .126 \\
& Factor 4 & & & -.002 & -.121 & .904 \\
\hline
\end{tabular}

The results of the regression analysis carried out to examine the effects of Perceived Teacher Behavior factors, on Self-Esteem are provided on the Table 9 . The regression model created according to the results of the analysis was found to be statistically significant $(\mathrm{p}<0.05)$.

When the coefficient was examined in the model, it was found that Factor 2 had a negative effect on Self-Esteem $(\mathrm{B}=-.020 ; \mathrm{p}<0.05) .7 \%$ of the change in Self-Esteem is explained by Factor 2.

Table 10. Investigation of the effects of perceived teacher behavior factors on the nature of learning (regression)

\begin{tabular}{llllllll}
\hline Dependent Var. & Independent Var. & $\mathrm{F}$ & $\mathrm{p}$ & Coefficient (B) & $\mathrm{t}$ & $\mathrm{p}$ & $\mathrm{R}^{2}$ \\
\hline The Nature of Learning & Constant & 12.816 & .000 & 18.950 & 9.291 & .000 & 0.146 \\
& Factor 1 & & & .254 & 5.503 & $.000^{*}$ & \\
& Factor 2 & & & .115 & 2.655 & $.008^{*}$ & \\
& Factor 3 & & & -.283 & -5.007 & $.000^{*}$ & \\
\hline & Factor 4 & & & .043 & .431 & .667 & \\
\hline
\end{tabular}


The results of the regression analysis conducted to investigate the effect of Perceived Teacher Behavior factors on the Nature of Learning are provided on the Table 10. The regression model created according to the results of the analysis was found to be statistically significant $(\mathrm{p}<0.05)$.

When the coefficient was examined in the model, it was found that Factor 1 and Factor 2 positively affected the Nature of Learning $(\mathrm{B}=.254 ; \mathrm{B}=.115 \mathrm{p}<0.05)$ while the Factor 3 negatively affected it $(\mathrm{B}=-.283 ; \mathrm{p}<0.05) .15 \%$ of the change in the nature of learning is explained by Factor 1, Factor 2, and Factor 3.

Table 11. Investigation of the effect of perceived teacher behavior on learning anxiety (regression)

\begin{tabular}{llllllll}
\hline Dependent Var. & Independent Var. & $\mathrm{F}$ & $\mathrm{p}$ & Coefficient (B) & $\mathrm{t}$ & $\mathrm{p}$ & $\mathrm{R}^{2}$ \\
\hline Learning-Related Anxiety & Constant & 19.176 & .000 & 60.732 & 19.341 & .000 & 0.203 \\
& Factor 1 & & & .012 & .173 & .863 & \\
& Factor 2 & & & -.214 & -3.220 & $.001^{*}$ & $.006^{*}$ \\
& Factor 3 & & & -.240 & -2.758 & -2.495 & $.013^{*}$ \\
& Factor 4 & & & -.382 & -2.45 & \\
\hline
\end{tabular}

The results of the regression analysis conducted to investigate the effect of Perceived Teacher Behavior factors on Learning Anxiety are provided on the Table 11. The regression model created according to the results of the analysis was found to be statistically significant $(\mathrm{p}<0.05)$.

When the coefficient was examined in the model, it was found that Factor 2, Factor 3 and Factor 4 negatively affected Learning Anxiety $(\mathrm{B}=-.214 ; \mathrm{B}=-.240 ; \mathrm{B}=-.382 \mathrm{p}<0.05) .20 \%$ of the change in Learning Anxiety is explained by Factor 2, Factor 3 and Factor 4.

Table 12. Investigation of the effect of perceived teacher behavior factors on expectation (regression)

\begin{tabular}{llllllll}
\hline Dependent Var. & Independent Var. & $\mathrm{F}$ & $\mathrm{p}$ & Coefficient (B) & $\mathrm{t}$ & $\mathrm{p}$ & $\mathrm{R}^{2}$ \\
\hline Expectation & Constant & 16.720 & .000 & 15.266 & 5.773 & .000 & 0.182 \\
& Factor 1 & & & .161 & 2.697 & $.007^{*}$ & \\
& Factor 2 & & & .288 & 5.154 & $.000^{*}$ \\
& Factor 3 & & & -.165 & -2.259 & $.025^{*}$ \\
& Factor 4 & & & .241 & 1.873 & .062 \\
\hline
\end{tabular}

The results of the regression analysis conducted to investigate the effect of Perceived Teacher Behavior factors on the Expectation are provided on the Table 12. The regression model created according to the results of the analysis was found to be statistically significant $(\mathrm{p}<0.05)$.

When the coefficient was examined in the model, it was found that the Factor 1 and Factor 2 had a positive effect on Expectation $(\mathrm{B}=.161 ; \mathrm{B}=.288 \mathrm{p}<0.05)$ while Factor 3 negatively affected it $(\mathrm{B}=-.165 ; \mathrm{p} 0.05) .18 \%$ of the change in expectation is explained by Factor 1, Factor 2 and Factor 3.

Table 13. Investigation of the effect of perceived teacher behavior factors on openness (regression)

\begin{tabular}{llllllll}
\hline Dependent Var. & Independent Var. & $\mathrm{F}$ & $\mathrm{p}$ & Coefficient (B) & $\mathrm{t}$ & $\mathrm{p}$ & $\mathrm{R}^{2}$ \\
\hline Openness & Constant & 17.467 & .000 & 19.078 & 7.029 & .000 & 0.188 \\
& Factor 1 & & & .167 & 2.725 & $.007^{*}$ & \\
& Factor 2 & & & .130 & 2.258 & $.025^{*}$ \\
& Factor 3 & & & .013 & .179 & .858 \\
& Factor 4 & & & .269 & 2.034 & $.043^{*}$ \\
\hline
\end{tabular}

The results of the regression analysis conducted to investigate the effect of Perceived Teacher Behavior factors on Openness are provided on the Table 13. The regression model created according to the results of the analysis was found to be statistically significant $(\mathrm{p}<0.05)$.

When the coefficient was examined in the model, it was determined that Factor 1, Factor 2 and Factor 4 negatively affected Openness $(\mathrm{B}=.167 ; \mathrm{B}=.130 ; \mathrm{B}=.269 ; \mathrm{p}<0.05) .19 \%$ of the change in Openness is explained by Factor 1, Factor 2 and Factor 4. 


\section{Discussion}

The findings of the present study, which was designed to investigate the effects of perceived teacher behaviors on students' self-esteem and attitudes towards learning, showed that teacher attitudes have different effects on self-esteem and attitudes towards learning, while they indicated that although the perception of negative attitudes may have short-term positive results contrary to expectations, it may adversely affect students' subsequent developmental periods.

The correlation analysis results of the research displayed that there is a weak negative relationship between all sub-dimensions of perceived teacher attitudes and self-esteem. Within these dimensions, other than Factor 2 which describes (warm, interested, democratic positive teacher behaviors), Factor 1 (discipline and rejection), Factor 3 (discipline double bind belittling indifference) and Factor 4 (demand-high expectation sexual abuse respect to individuality) define negative teacher behaviors. Contrary to expectations, the negative relationship between perceived teacher behaviors and self-esteem and the teacher behaviors explained by Factor 2 (warm, interested, democratic positive teacher behaviors suggests that the student-teacher relationship should also be evaluated considering that it symbolizes the relationships of adolescent-authority figure. Related research reveals that whereas teachers' warm and concerned behaviors positively affect the self-esteem in students, several factors including family and peer relationships and student's personality traits also affect the self-esteem (Baumeister, Campbell, Krueger, \& Vohs, 2003). Therefore, while a positive relationship is expected between positive, warm, concerned and accepted teacher behaviors and self-esteem (Darling, Hamilton, \& Niego, 1994; Leary, Tambor, Terdal, \& Downs, 1995; Leary \& Baumeister, 2000; Frenzel, Goetz, Lüdtke, Pekrun, \& Sutton, 2009), the negative relationship draws attention to whether students carry the sense of trust towards the relationship with the meaning they bear for teacher behaviors (Wooten \& McCroskey, 1996; Gamlem \& Smith, 2013), in other words, to students' perception of the reliability of teachers. Besides, the finding explaining the effect of perceived teacher attitude sub-dimensions on self-esteem is in parallel with the fact that the Factor 2 (warm, interested, democratic positive teacher behaviors) dimension of the perceived teacher behavior negatively affects self-perception and $7 \%$ of the change in self-esteem is explained by this factor; when the finding is interpreted by taking interdisciplinary studies into consideration, it raises the question of which behaviors are socially accepted as the proof of being cared and which behaviors are acquired in the process of socialization. From another dimension, it can be said that students may experience the consequences of negative behaviors they see from teachers in the long term, as stated in the literature on abuse, and that longitudinal studies are needed. In addition, descriptive statistics of students' perceived teacher behavior scale points out that negative attitudes that students perceive in their teachers are high. According to the results of the correlation analysis of the attitudes towards learning and self-esteem and perceived teacher behaviors, there were relationships in different directions and at different levels between the sub-dimensions explaining the attitudes towards learning and the related scale dimensions. According to the findings, there is a weak positive relationship between the anxiety dimension of learning attitudes and self-esteem, and a weak negative relationship between the expectation and self-esteem. The result shows that as anxiety about learning increases, self-esteem increases, and self-esteem decreases as the expectations towards behaviors and expectations about learning new things increase. The results suggest that in adolescence, students' anxiety levels produced feedback on their own competencies, that coping with learning situations that could produce failure anxiety increased strong, valuable and positive perceptions about themselves (Greenberg, Solomon, Pyszczynski, Rosenblatt, Burling, Lyon, ... Pinel, 1992), but in a sense, learning experiences that could represent future expectations can produce disappointment, and their tendency to short-term gains can make them feel better. The related studies suggest that while anxiety positively affects the development of identity by supporting learning at a certain level, it shows that young people's expectations for long-term goals depend on many psycho-social factors (Wentzel, 1994; Bandura, 1996; Braun, Jackson, \& Wiley, 2001; Urdan \& Schoenfelder, 2006).

Findings related to the relationship between perceived teacher attitudes and learning-related attitudes reveal that there is a positive weak relationship between the nature of learning and perceived teacher attitudes, and all the sub-dimensions except Factor 3 (discipline double bind belittling indifference); a moderate negative correlation between the anxiety sub-dimension of learning attitudes and the perceived teacher behaviors scale, and all the sub-dimensions; a moderate positive correlation between expectation sub-dimension of learning attitudes and perceived teacher behaviors scale, and its sub-dimension Factor 2 (warm, interested, democratic positive self concept), and a weak positive correlation with Factor 1(discipline-rejection), Factor 3 (discipline double bind belittling indifference) and Factor 4 (demand-high expectation sexual abuse respect to individuality), and a positive correlation between Factor 2 (warm, interested, democratic positive self concept) Factor 3 (discipline double bind belittling indifference) and Factor 4 (demand-high expectation sexual abuse respect to individuality); a moderate positive correlation between the openness sub-dimension of learning attitudes and perceived teacher 
behaviors scale, and all three sub-dimensions except Factor 2 (warm, interested, democratic positive self concept), and a weak positive correlation with Factor 2. Obtained findings indicate that the belief that learning is a natural process of human being is supported and expectations and openness towards learning are increased depending on the perceived negative teacher behaviors. Findings suggest that students can accept negative behaviors as the behaviors of interest in themselves and this may be related to schemes of interest and support behaviors of the culture in which they live (Bornstein, 1995; Lemerise \& Arsenio, 2000; Hofstede, 2001). Considering that the similar result was obtained with respect to self-esteem, the problem arises regarding the dynamics that the students' positive behavior definitions and properties that affect their interpersonal relationships such as trust, autonomy and so on are associated. The finding related to the anxiety dimension of the learning attitudes indicates that the anxiety of the learning decreases as the negativity of perceived teacher behaviors increases and the anxiety increases as the negative behaviors decrease. This finding supports the other findings with a different perspective. If students perceive the negative attitudes of teachers as interest, it can be considered natural that the students' negative attitudes and emotions regarding their success in the learning process increase as the interest of the teacher is reduced even if it is negative. Although the findings do not correspond to the related literature (Urdan, 1997; Noels, Clément, \& Pelletier, 1999; Kelsey, Kearney, Plax, Allen, \& Ritter, 2004; Lewis \& Riley, 2009; Goodboy \& Bolkan, 2009), there are also studies that have come up with similar results (Piekarska, 2000).

According to the results of the regression analysis conducted in accordance with the main purpose of the study, it negatively affects the perceived teacher attitudes and self-esteem negatively, while explaining $7 \%$ of the change in self-esteem. The results of the response level of self-esteem to the perceived teacher attitudes sub-dimensions illustrated that self-esteem is negatively affected and $7 \%$ of the change in self-esteem was explained by Factor 2 (warmth-acceptance, democratic positive self-concept). Although the finding creates the idea that negative teacher behaviors decrease self-esteem, it is noteworthy that perceived teacher behavior explaining the decrease in self-esteem is; Factor 2 that is, the qualitative dimension of positive teacher behaviors. The finding complies with the results of the correlation analysis results and the findings of the research on attitudes towards learning. On the other hand, as discussed in other findings, the importance of interdisciplinary studies emerges when we consider that schemes regarding negative behaviors belong to the group of young students who are trying to acquire the adulthood qualifications in adolescence. Moreover, considering that the consequences of being exposed to negative behaviors, especially the outcomes of psychological abuse, emerge in the long term, it is revealed that not only the schemes belonging to the teachers but also to the students and their families need to be differentiated (Emery \& Laumann-Billings, 2002; Lewis \& Riley; 2009; Higgins \& McCabe, 2000; Marlow, Goodman, Meltzer, \& Ford, 2013; Fromuth, Davis, Kelly, \& Wakefield, 2015). Considering the violent behaviors that have become more visible in the school environment in the last decade, resulting in individual and collective deaths of students as a result of students' violence towards other students and teachers (Steffgen, Recchia, \& Viechtbauer, 2013; Borofsky, Kellerman, Baucom, Oliver, \& Margolin, 2013; Benbenishty, Astor, Roziner, \& Wrabel, 2016), it is thought that false protective factor, that is, perceiving the negative behaviors as care and being deemed important deserves to be studied further.

Whereas perceived teacher behaviors positively affect the nature of learning, expectations and openness towards learning, they negatively affect the anxiety about learning. Perceived teacher behaviors explain $4 \%$ of the change in the nature of learning, $18 \%$ of the change in anxiety about learning, $10 \%$ of the change in expectation towards learning and $18 \%$ of the change in openness to learning. The obtained finding is consistent with the findings of the correlation analysis of perceived teacher behaviors and students' attitudes towards learning of the study. Therefore, it is thought that the students' perceived close attention in their teachers, schemes for caring behaviors (Davis, 2003) and social dynamics (Ajzen \& Fishbein, 1977) are related, and teachers' traditional and authoritarian education approaches cannot be evaluated independently of culture. In this context, although the results of the research do not show parallel results with the literature (Meece, Anderman, \& Anderman, 2006; Humphrey, 2013), it is possible to say that the finding is parallel with the results of interdisciplinary research (Korbin, 1991; Lemerise \& Arsenio, 2000; Garland, 2006).

Findings related to the effect of perceived teacher behaviors sub-dimensions on the sub-dimensions of learning attitudes showed that whereas perceived teacher behaviors Factor 1(discipline-rejection) and Factor 2 (warmth-acceptance, democratic positive self-concept) positively affected the nature of learning, Factor 3 (discipline double bind belittling indifference) negatively affected it and $15 \%$ of the change in the nature of learning was explained by these factors. In the anxiety about learning sub-dimensions of the perceived teacher behaviors, Factor 2 (warmth-acceptance, democratic positive self-concept), Factor 3 (discipline double bind belittling indifference) and Factor 4 (demand-high expectation sexual abuse respect to individuality) negatively affect anxiety about learning, and these dimensions explain $20 \%$ of the change in anxiety about learning. The 
results of the effect of perceived teacher attitudes sub-dimensions on the expectation dimension related to learning revealed that Factor 1 (discipline-rejection) and Factor 2 (warmth-acceptance, democratic positive self-concept) dimensions of the perceived teacher behaviors positively affect the expectation and Factor 3 (discipline double bind belittling indifference) negatively affect the expectation and $18 \%$ of the change in the expectation is explained by these factors. Finally, in the dimension of openness related to learning, it was seen that the dimensions other than Factor 3 (discipline double bind belittling indifference) of perceived teacher behaviors had a negative effect, and $19 \%$ of the openness to learning was explained by the related dimensions. While the results obtained are similar to each other, the change of students' motivation towards learning is perceived as negative motivation technique (Weijers, 2000; Smith, 2012); however, it is seen that negative attitudes that do not support long term performance affect attitudes towards learning. An example of this situation is seen in the effect of Factor 1 (discipline-rejection), which defines students' excessive discipline and rejection behaviors from perceived teacher attitudes, and Factor 2 (warmth-acceptance, democratic positive self-concept), which explains positive democratic attitudes, on the attitudes (nature of learning) and positive attitudes towards learning outcomes. In addition, when the finding related to openness to learning (Love, Roper, \& Vahter, 2014) is examined, it is understood that Factors 1 (discipline-rejection) and 2 (warmth-acceptance, democratic positive self-concept) have negative effects along with Factor 3 (discipline double bind belittling indifference). Therefore, it is possible to say that the negative attitudes of the teachers have short term effects on the attitudes towards learning with the negative motivation effect and that their longterm effect is negative, that is, the students are responsible for their own learning and teachers' negative attitudes do not support the development of students' attitudes towards learning in a way to manage their own learning. The studies of the related literature (Gorham \& Christopher, 1992; Deci, Koestner, \& Ryan, 2001) in different disciplines seem to support these ideas (Lemerise \& Arsenio, 2000; Garland, 2006).

\section{Conclusion and Suggestions}

Although the results of the study conducted to reveal the effect of perceived teacher behaviors on students' self-esteem and attitudes towards learning has revealed findings that do not overlap with the related literature, it has the quality to add a different dimension to the studies related to the subject. According to the results of the study, perceived negative teacher attitudes show a positive relationship with self-esteem and attitude towards learning. In addition, it has been revealed that there is a positive relationship between self-esteem and the anxiety about learning, and a weak negative relationship between self-esteem and the expectation regarding learning. It was found that one of the sub-dimensions of teacher attitudes, which included warmth, interest, democratical acceptance and support explaining positive attitudes and behaviors, negatively affects self-esteem and, $7 \%$ of the change in self-esteem was explained by this factor.

It was concluded that perceived teacher behaviors and their sub-scales have a weak negative relationship with the factors except Factor 2 and a moderate negative relationship with Factor 2 which explains the positive behaviors towards attitudes to learning and anxiety about learning. It was seen that perceived teacher behaviors explained $18 \%$ of the change in anxiety, that the sub-dimensions Factor 2, Factor 3 and Factor 4 negatively affected anxiety, and that these factors explained $20 \%$ of the change in anxiety about learning.

It was found that there was a weak positive relationship between the nature of learning, which is among the sub-dimensions of learning, and the dimensions explaining teacher behaviors other than Factor 3, and $4 \%$ of the changes in the nature of learning is explained. Besides while Factor 1 and Factor 2 sub-dimensions positively affected the nature of learning, Factor 3 negatively affected it and 15\% of these factors were found to explain the change in the nature of learning.

According to the results of the analysis on the relationship between perceived teacher behaviors and the expectation about learning sub-dimension of the attitudes towards learning, the perceived teacher attitude has a moderate positive relationship with Factor 2 and a weak positive relationship with Factor 1, Factor 2 and Factor 4. It was also seen that $10 \%$ of the change in the expectation about learning sub-dimension was explained by perceived teacher behaviors; expectation about learning was positively affected by Factor 1, Factor 2 and negatively affected by Factor 3 , and $10 \%$ of the change in this dimension was explained by these factors.

It was found that openness to learning dimension of the attitudes towards learning has a moderate positive relationship with the dimensions of the perceived teacher behaviors other than Factor 2 and a weak positive relationship with Factor 2. Besides, $18 \%$ of the change in the openness to learning was explained by perceived teacher behaviors and among its sub-dimensions, the factors except Factor 3 have a negative effect on openness to learning and that these Factor 1, Factor 2 and Factor 3 explained 19\% of the change in the dimension of openness to learning. 
When the findings of the study are evaluated in general, it is seen that, in the perceived teacher behavior scale, positive teacher behaviors with warm, interested and democratic behavioral patterns have a reducing effect on self-esteem. On the other hand, teachers' disciplined, repudiative behaviors, insulting behaviors with high expectancy, together with positive warm interest behaviors have reducing negative effects on openness to learning dimension of attitudes towards learning, which explains the motivation towards learning new subjects. According to the findings, it is possible to say that the negative teacher behaviors serve as a driving force and for the need for proving oneself, for the students which are subject to the negative behaviors. Besides, the driving force in question can be seen as one of the factors that trigger the psycho-social risk susceptibility of students in adolescence and later development periods, by negatively affecting their self-esteem and desire to learn new things.

The results of the study show that negative teacher behaviors have positive effects on self-esteem and attitudes towards learning. The findings indicate that traditional and authoritarian attitudes are perceived as warmth, interest and support in the context of social dynamics. Considering the long-term effects of exposure to negative behaviors and that the working group consists of adolescents, it is suggested that interdisciplinary studies should reveal the questions of which behaviors should be acquired by the children and adolescents during the socialization process, besides the questions regarding the mental health of the youth who will constitute the adult human resource of the society in the future. The results of the study highlight socio-cultural dynamics in the context of teacher-student relations. Considering that the teachers are members of the society and that their attitudes and schemas about the target behaviors of the students cannot develop independent from the societal dynamics, the importance of accelerating the studies that will support a healthy development in accordance with the aims of the educational institution become apparent.

\section{References}

Ajzen, I., \& Fishbein, M. (1977). Attitude-behavior relations: A theoretical analysis and review of empirical research. Psychological Bulletin, 84(5), 888-918. https://doi.org/10.1037/0033-2909.84.5.888

Alantar, M. (1989). Psychological maltreatment: An attempt of its definition by experts and its assessment among a group of adolescents. Unpublished Thesis, Bosphorous University.

Baumeister, R. F., Campbell, J. D., Krueger, J. I., \& Vohs, K. D. (2003). Does high self-esteem cause better performance, interpersonal success, happiness, or healthier lifestyles? Psychological Science in the Public Interest, 4(1), 1-44. https://doi.org/10.1111/1529-1006.01431

Benbenishty, R., Astor, R. A., Roziner, I., \& Wrabel, S. L. (2016). Testing the causal links between school climate, school violence, and school academic performance: A cross-lagged panel autoregressive model. Educational Researcher, 45(3), 197-206. https://doi.org/10.3102/0013189X16644603

Bornstein, M. H. (1995). Form and function: Implications for studies of culture and human development. Culture \& Psychology, 1(1), 123-137. https://doi.org/10.1177/1354067X9511009

Borofsky, L. A., Kellerman, I., Baucom, B., Oliver, P. H., \& Margolin, G. (2013). Community violence exposure and adolescents' school engagement and academic achievement over time. Psychology of Violence, 3(4), 381. https://doi.org/10.1037/a0034121

Braun, H. I., Jackson, D. N., \& Wiley, D. E. (2001). Socially desirable responding: The evolution of a construct. In The role of constructs in psychological and educational measurement (pp. 61-84). Routledge. https://doi.org/10.4324/9781410607454

Brendgen, M., Wanner, B., \& Vitaro, F. (2006). Verbal abuse by the teacher and child adjustment from kindergarten through grade 6. Pediatrics, 117(5), 1585-1598, https://doi.org/10.1542/peds.2005-2050

Burnett, P. C. (1999). Children's Self - Talk and Academic Self - Concepts: The impact of teachers' statements. Educational Psychology in Practice, 15(3), 195-200. https://doi.org/10.1080/0266736990150308

Çakar, Y. (1994). The Construction of Perceived Teacher Behavior Inventory. Unpublished Master Thesis, Bosphorous University.

Campbell, J. R., \& Verna, M. A. (2007). Effective parental influence: Academic home climate linked to children's achievement. Educational Research and Evaluation, 13(6), 501-519. https://doi.org/10.1080/13803610701785949

Chen, J. K., \& Wei, H. S. (2011). Student victimization by teachers in Taiwan: Prevalence and associations. Child Abuse \& Neglect, 35(5), 382-390. https://doi.org/10.1016/j.chiabu.2011.01.009

Çuhadaroğlu, F. (1986). Adolesanlarda benlik saygısı. Unpublished Thesis, Hacettepe Üniversitesi Tip Fakültesi 
Psikiyatri Anabilim Dalı, Ankara.

Davis, H. A. (2003). Conceptualizing the role and influence of student-teacher relationships on children's social and cognitive development. Educational Psychologist, 38(4), 207-234. https://doi.org/10.1207/S15326985EP3804_2

De Carlo, L. T. (1997). On the Meaning and Use of Kurtosis. Psychological Methods, 2, 292-307. https://doi.org/10.1037/1082-989X.2.3.292

Elbedour, S., Assor, A., Center, B. A., \& Maruyama, G. M. (1997). Physical and psychological maltreatment in schools: The abusive behaviors of teachers in Bedouin schools in Israel. School Psychology International, 18(3), 201-215. https://doi.org/10.1177/0143034397183002

Ellison, C. G., \& Bradshaw, M. (2009). Religious beliefs, sociopolitical ideology, and attitudes toward corporal punishment. Journal of Family Issues, 30(3), 320-340. https://doi.org/10.1177/0192513X08326331

Emery, R. E., \& Laumann-Billings, L. (2002). Child abuse. In M. Rutter \& E. Taylor (Eds.), Child and adolescent psychiatry (4th ed., pp. 325-339). Oxford: Blackwell Science.

Feuerborn, L., \& Chinn, D. (2012). Teacher perceptions of student needs and implications for positive behavior supports. Behavioral Disorders, 37(4), 219-231. https://doi.org/10.1177/019874291203700403

Fields, B. A. (1986). The nature and incidence of classroom behaviour problems and their remediation through preventive management. Behaviour Change, 3(1), 53-57. https://doi.org/10.1017/S0813483900009116

Frenzel, A. C., Goetz, T., Lüdtke, O., Pekrun, R., \& Sutton, R. E. (2009). Emotional transmission in the classroom: Exploring the relationship between teacher and student enjoyment. Journal of Educational Psychology, 101(3), 705-716. https://doi.org/10.1037/a0014695

Fromuth, M. E., Davis, T. L., Kelly, D. B., \& Wakefield, C. (2015). Descriptive features of student psychological maltreatment by teachers. Journal of Child \& Adolescent Trauma, 8(2), 127-135. https://doi.org/10.1007/s40653-015-0042-3

Gamlem, S. M., \& Smith, K. (2013). Student perceptions of classroom feedback. Assessment in Education: Principles, Policy \& Practice, 20(2), 150-169. https://doi.org/10.1080/0969594X.2012.749212

Garland, D. (2006). Concepts of culture in the sociology of punishment. Theoretical Criminology, 10(4), 419-447. https://doi.org/10.1177/1362480606068873

Goodboy, A. K., \& Bolkan, S. (2009). College teacher misbehaviors: Direct and indirect effects on student communication behavior and traditional learning outcomes. Western Journal of Communication, 73(2), 204 219. https://doi.org/10.1080/10570310902856089

Gorham, J., \& Christophel, D. M. (1992). Students' perceptions of teacher behaviors as motivating and demotivating factors in college classes. Communication Quarterly, 40(3), 239-252. https://doi.org/10.1080/01463379209369839

Gray-Little, B., Williams, V. S., \& Hancock, T. D. (1997). An item response theory analysis of the Rosenberg Self-Esteem Scale. Personality and Social Psychology Bulletin, 23(5), 443-451. https://doi.org/10.1177/0146167297235001

Greenberg, J. L., Solomon, S., Pyszczynski, T., Rosenblatt, A., Burling, J., Lyon, D., ... Pinel, E. (1992). Why Do People Need Self-Esteem? Converging Evidence That Self-Esteem Serves an Anxiety-Buffering Function. Journal of Personality and Social Psychology, 63(6), 913-922. https://doi.org/10.1037/0022-3514.63.6.913

Groeneveld, R. A., \& Meeden, G. (1984). Measuring Skewness and Kurtosis. The Statistician, 33, 391-399. https://doi.org/10.2307/2987742

Higgins, D. J., \& McCabe, M. P. (2000). Multi - type maltreatment and the long - term adjustment of adults. Child Abuse Review: Journal of the British Association for the Study and Prevention of Child Abuse and Neglect, 9(1), 6-18. https://doi.org/10.1002/(SICI)1099-0852(200001/02)9:1<6::AID-CAR579>3.0.CO;2-W

Hofstede, G. (2001). Culture's consequences: Comparing values, behaviors, institutions and organizations across nations. Sage publications.

Hopkins, K. D., \& Weeks, D. L. (1990). Tests for normality and measures of skewness and kurtosis: Their place in research reporting. Educational and Psychological Measurement, 50(4), 717-729. https://doi.org/10.1177/0013164490504001

Humphrey, G. (2013). The nature of learning: In its relation to the living system. Routledge. 
https://doi.org/10.4324/9781315009261

Hyman, I. A., \& Perone, D. C. (1998). The other side of school violence: Educator policies and practices that may contribute to student misbehavior. Journal of School Psychology, 36(1), 7-27. https://doi.org/10.1016/S0022-4405(97)87007-0

Kara, A. (2010). Öğrenmeye ilişkin tutum ölçeğinin geliştirilmesi. Elektronik Sosyal Bilimler Dergisi, 9(32), 4962.

Karasar, N. (2007). Bilimsel Araştırma Yöntemi (17. Baskı). Nobel Yayın Dağıtım Ltd. Şti. Ankara.

Kearney, P., Plax, T. G., Hays, E. R., \& Ivey, M. J. (1991). College teacher misbehaviors: What students don't like about what teachers say and do. Communication Quarterly, 39(4), 309-324. https://doi.org/10.1080/01463379109369808

Kelsey, D. M., Kearney, P., Plax, T. G., Allen, T. H., \& Ritter, K. J. (2004). College students' attributions of teacher misbehaviors. Communication Education, 53(1). https://doi.org/10.1080/0363452032000135760

Korbin, J. E. (1991). Cross-cultural perspectives and research directions for the 21st century. Child Abuse \& Neglect, 15, 67-77. https://doi.org/10.1016/0145-2134(91)90010-B

Kurtz, P. D., Gaudin Jr, J. M., Wodarski, J. S., \& Howing, P. T. (1993). Maltreatment and the school-aged child: School performance consequences. Child Abuse \& Neglect, 17(5), 581-589. https://doi.org/10.1016/0145-2134(93)90080-O

Leary, M. R., \& Baumeister, R. F. (2000). The nature and function of self-esteem: Sociometer theory. Advances in Experimental Social Psychology, 32, 1-62. https://doi.org/10.1016/S0065-2601(00)80003-9

Leary, M. R., Tambor, E. S., Terdal, S. K., \& Downs, D. L. (1995). Self-esteem as an interpersonal monitor: The sociometer hypothesis. Journal of Personality and Social Psychology, 68(3), 518-530. https://doi.org/10.1037/0022-3514.68.3.518

Lemerise, E. A., \& Arsenio, W. F. (2000). An integrated model of emotion processes and cognition in social information processing. Child Development, 71(1), 107-118. https://doi.org/10.1111/1467-8624.00124

Lewis, R. (2001). Classroom discipline and student responsibility: The students' view. Teaching and Teacher Education, 17(3), 307-319. https://doi.org/10.1016/S0742-051X(00)00059-7

Lewis, R., \& Riley, P. (2009). Teacher Misbehaviour. In L. J. Saha \& A. G. Dworkin (Eds.), International Handbook of Research on Teachers and Teaching (Springer International Handbooks of Education, vol 21). Springer, Boston, MA. https://doi.org/10.1007/978-0-387-73317-3_27

Love, J. H., Roper, S., \& Vahter, P. (2014). Learning from openness: The dynamics of breadth in external innovation linkages. Strategic Management Journal, 35(11), 1703-1716. https://doi.org/10.1002/smj.2170

Marlow, R., Goodman, R., Meltzer, H., \& Ford, T. (2013). Influence of problematic child-teacher relationships on future psychiatric disorder: population survey with 3-year follow-up. The British Journal of Psychiatry, 202(5), 336-341. https://doi.org/10.1192/bjp.bp.112.120741

McEachern, A. G., Aluede, O., \& Kenny, M. C. (2008). Emotional abuse in the classroom: Implications and interventions for counselors. Journal of Counseling \& Development, 86(1), 3-10. https://doi.org/10.1002/j.1556-6678.2008.tb00619.x

Meece, J. L., Anderman, E. M., \& Anderman, L. H. (2006). Classroom goal structure, student motivation, and academic achievement. Annual Review of Psychology, 57, 487-503. https://doi.org/10.1146/annurev.psych.56.091103.070258

Miller, J. G. (1984). Culture and the development of everyday social explanation. Journal of Personality and Social Psychology, 46(5), 961-978. https://doi.org/10.1037/0022-3514.46.5.961

Moors, J. J. A. (1986). The Meaning of Kurtosis: Darlington Reexamined. The American Statistician, 40, $283-$ 284. https://doi.org/10.1080/00031305.1986.10475415

Noels, K. A., Clément, R., \& Pelletier, L. G. (1999). Perceptions of teachers' communicative style and students' intrinsic and extrinsic motivation. The Modern Language Journal, 83(1), 23-34. https://doi.org/10.1111/0026-7902.00003

Piekarska, A. (2000). School stress, teachers' abusive behaviors, and children's coping strategies. Child Abuse \& Neglect, 24(11), 1443-1449. https://doi.org/10.1016/S0145-2134(00)00201-5 
Riley, P. (2010). Attachment theory and the teacher-student relationship: A practical guide for teachers, teacher educators and school leaders. Routledge. https://doi.org/10.4324/9780203845783

Roorda, D. L., Koomen, H. M., Spilt, J. L., \& Oort, F. J. (2011). The influence of affective teacher-student relationships on students' school engagement and achievement: A meta-analytic approach. Review of Educational Tesearch, 81(4), 493-529. https://doi.org/10.3102/0034654311421793

Sava, F. A. (2002). Causes and effects of teacher conflict-inducing attitudes towards pupils: A path analysis model. Teaching and Teacher Education, 18(8), 1007-1021. https://doi.org/10.1016/S0742-051X(02)00056-2

Shields, C., \& Gredler, M. (2003). A problem-solving approach to teaching operant conditioning. Teaching of Psychology, 30(2), 114-116. https://doi.org/10.1207/S15328023TOP3002_06

Shweder, R. A., \& Sullivan, M. A. (1993). Cultural psychology: Who needs it? Annual Review of Psychology, 44(1), 497-523. https://doi.org/10.1146/annurev.ps.44.020193.002433

Slade, E. P., \& Wissow, L. S. (2007). The influence of childhood maltreatment on adolescents' academic performance. Economics of Education Review, 26(5), 604-614. https://doi.org/10.1016/j.econedurev.2006.10.003

Smith, P. (2012). Punishment and Meaning: The Cultural Sociological. The SAGE Handbook of Punishment and Society, 114. https://doi.org/10.4135/9781446247624.n6

Snook, I. A. H. P. A. (1999). Dangerous schools: What we can do about the physical and emotional abuse of our children. Jossey-Bass.

Steffgen, G., Recchia, S., \& Viechtbauer, W. (2013). The link between school climate and violence in school: A meta-analytic review. Aggression and Violent Behavior, 18(2), 300-309. https://doi.org/10.1016/j.avb.2012.12.001

Sutton, J., Smith, P. K., \& Swettenham, J. (1999). Social cognition and bullying: Social inadequacy or skilled manipulation? British Journal of Developmental Psychology, 17(3), 435-450. https://doi.org/10.1348/026151099165384

Urdan, T. C. (1997). Examining the relations among early adolescent students' goals and friends' orientation toward effort and achievement in school. Contemporary Educational Psychology, 22(2), 165-191. https://doi.org/10.1006/ceps.1997.0930

Wang, M. T., Selman, R. L., Dishion, T. J., \& Stormshak, E. A. (2010). A tobit regression analysis of the covariation between middle school students' perceived school climate and behavioral problems. Journal of Research on Adolescence, 20(2), 274-286. https://doi.org/10.1111/j.1532-7795.2010.00648.x

Way, N., Reddy, R., \& Rhodes, J. (2007). Students' perceptions of school climate during the middle school years: Associations with trajectories of psychological and behavioral adjustment. American Journal of Community Psychology, 40(3-4), 194-213. https://doi.org/10.1007/s10464-007-9143-y

Wayne, A. J., \& Youngs, P. (2003). Teacher characteristics and student achievement gains: A review. Review of Educational Research, 73(1), 89-122. https://doi.org/10.3102/00346543073001089

Weijers, I. (2000). Punishment and Upbringing: Considerations for an educative justification of punishment. Journal of Moral Education, 29(1), 61-73. https://doi.org/10.1080/030572400102934

Wentzel, K. R. (1994). Relations of social goal pursuit to social acceptance, classroom behavior, and perceived social support. Journal of Educational Psychology, 86(2), 173-182. https://doi.org/10.1037/0022-0663.86.2.173

Wooten, A. G., \& McCroskey, J. C. (1996). Student trust of teacher as a function of socio - communicative style of teacher and socio - communicative orientation of student. Communication Research Reports, 13(1), 94 100. https://doi.org/10.1080/08824099609362075

Yuns, O. I. (2011). Teacher-student relationship factor affecting motivation and academic achievement in ESL classroom. Procedia - Socail and Behavioral Sciences, 15, 2637-2641. https://doi.org/10.1016/j.sbspro.2011.04.161

Zimmerman, B. J., Bonner, S., \& Kovach, R. (1996). Psychology in the classroom: A series on applied educational psychology. Developing self-regulated learners: Beyond achievement to self-efficacy. Washington, DC, US: American Psychological Association. https://doi.org/10.1037/10213-000 


\section{Copyrights}

Copyright for this article is retained by the author, with first publication rights granted to the journal.

This is an open-access article distributed under the terms and conditions of the Creative Commons Attribution license (http://creativecommons.org/licenses/by/4.0/). 